\title{
DESIGN OF SQUARE PATCH ANTENNA FOR KA BAND
}

\author{
V. CHINNAMMAL ${ }^{1} \&$ DR. P. JOTHILAKSHMI ${ }^{2}$ \\ ${ }^{I}$ Assistant Professor, Rajalakshmi Institute of Technology, Chennai, India \\ ${ }^{2}$ Professor, Sri Venkateswara College of Engineering, Chennai, India
}

\begin{abstract}
Here, the document comprises of the layout of antenna used for Ka band whose frequency range is from $26-40$ GHz. The planned aerial is comprehended by employing a single and dual dielectric substrate material as FR-4 with permittivity of 4.4. The aerial is provided with a microstrip line feed having an impedance of 50 ohms. Generally lots of antenna system employs Microstrip Patch Antenna (MPA) owing to its insubstantial weight, low profile, low cost, easy to fabricate etc. The simulations are done by using CST Simulation Studio tool. The feigned figures of Return Loss, VSWR, Energy of Power and Gain are revealed below

KEYWORDS: Square Patch Antenna, Microstrip Patch Antenna (MPA)
\end{abstract}

Received: Jun 09, 2020; Accepted: Jun 29, 2020; Published: Jun 30, 2020; Paper Id.: IJMPERDJUN2020301

\section{INTRODUCTION}

As the microstrip patch antennas have several good-looking applications like Wireless, Radars, Satellites, mobile communications etc. But it undergoes with the problems like surface waves, narrow bandwidth, large IR loss and low gain. Gain means that the quantity of energy emitted in specific direction in relevance to the energy emitted in an isotropic direction. Therefore to have a progressive gain, the apt option is to use dual layer of substrate patch antennas. So as to attain this, the numbers of practices in use are triple layer of substrate, sandwiched layer of substrate apart from this gain can be enhanced with the help of multiband antennas obtained by fractal geometries, inserting slots into the patch, parasitic elements, discrete multi-loop planar antennas, EBG (Electromagnetic Band Gap) structures, stacked patch antennas etc.

At the present time, multiband patch antennas are examined due to its coverage like GSM, DCS, CDMA and PCS. So the PIN diodes, switches and varactor diodes are utilized for multiband function. These techniques are working with reconfigurable frequency of two states. i.e. ON \& OFF. Other than this, slots on the patch are controlled by the switches are also incorporated in it.

A multiband operation could also be attained by adjusting the ground plane, by devising an array, etc. which gives the way to improve bandwidth and gain of the antenna.

Here, a square shaped patch aerial is planned and used for different applications. The planned aerial be capable of working in the range of frequency from 26-40GHz. A VSWR below 2 is achieved for both the substrates (Single FR-4 \& Dual FR-4). 


\section{ANTENNA DESIGN}

The devised antenna has square patch placed on the FR-4 substrate with the permittivity of 4.4, which is revealed in the figure 1. It has a ground plane, FR-4 substrate and conducting patch as the structure of the aerial. Figure 2 illustrates about the planned aerial that has double layer of dielectric substrate FR-4. The aerial is comprehended by microstrip line feed of $50 \mathrm{ohms}$. On the whole the planned aerial has the size of $13.15 \mathrm{~mm}$ x $10.92 \mathrm{~mm}$. Table 1 shows the size of the planned aerial. Based on the resonance frequencies and dimension, the patch antenna's performance is revealed. The Return Loss, VSWR, directivity as well as gain are represented in the results part.

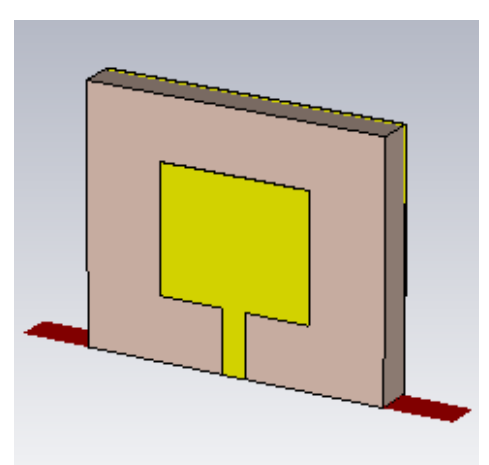

Figure 1: Aerial with Single FR 4 Substrate.

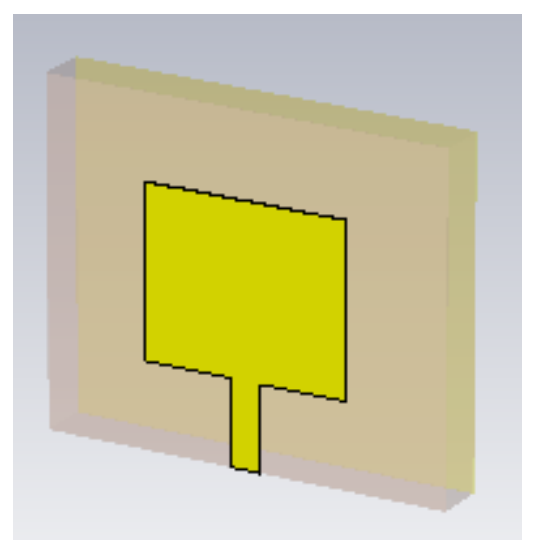

Figure 2: Aerial with Dual FR-4 Substrate.

Table 1: Aerial's Size Parameters

\begin{tabular}{|c|c|c|}
\hline S. No. & Antenna Parameters & Dimensions(mm) \\
\hline 1 & $\mathrm{~W}_{\mathrm{g}}$ & 13.15 \\
\hline 2 & $\mathrm{~L}_{\mathrm{g}}$ & 10.92 \\
\hline 3 & $\mathrm{~W}_{\mathrm{p}}$ & 6.575 \\
\hline 4 & $\mathrm{~L}_{\mathrm{p}}$ & 5.46 \\
\hline 5 & $\mathrm{~h}_{\mathrm{s}}$ & 1.6 \\
\hline 6 & $\mathrm{~L}_{\mathrm{eff}}$ & 2.52 \\
\hline 7 & $€_{\mathrm{reff}}$ & 4.53 \\
\hline 8 & $\Delta \mathrm{L}$ & 0.601 \\
\hline
\end{tabular}

\section{SIMULATION OUTCOME AND REVIEW}

The planned aerial is simulated with the help of CST tool which is employing the Finite Integration Technique (FIT). The Time Domain Solver computes the behavior of the aerial in a one run with an arbitrarily fine frequency resolution. The transient analysis of the planned aerial is performed through hexahedral mesh type. 


\section{Return Loss}

The feigned return loss $\left(S_{11}\right)$ for jointly the planned aerial is revealed in figure 3 and figure 4 . The planned aerial has the resonance frequency of $25 \mathrm{GHz}$ with return loss of $-25.17 \mathrm{~dB}$ for single FR-4 and return loss of $-24.0 \mathrm{~dB}$ for dual FR-4 substrate. The return loss plays a vital role in the impedance matching.

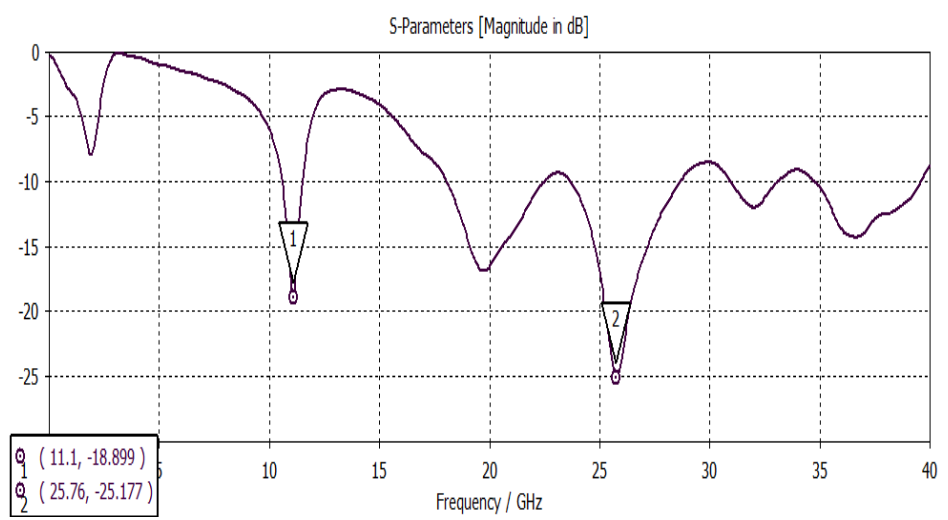

Figure 3: Return Loss for Single FR 4 Substrate.

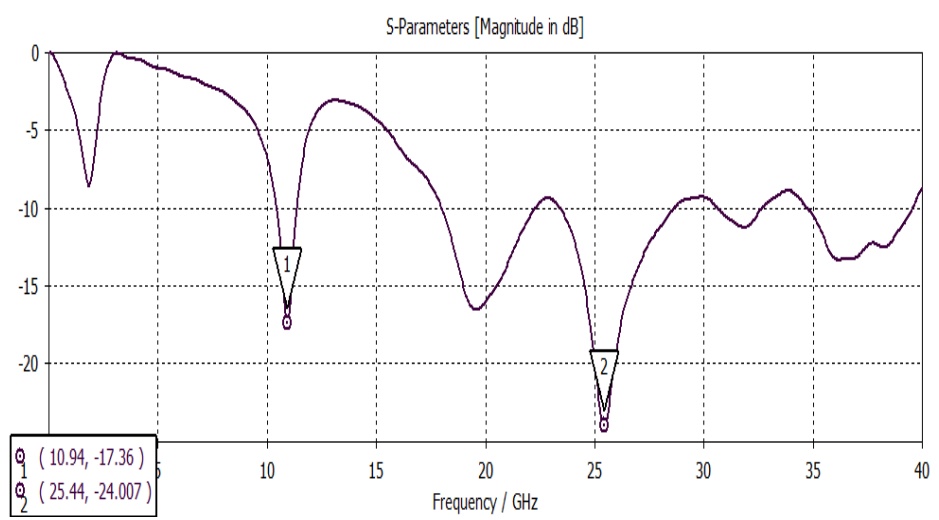

Figure 4: Return Loss for Dual FR 4 Substrate.

\section{VSWR}

The simulated VSWR jointly with the planned aerial are shown in the figure 5 and figure 6 . VSWR is needed to decide the characteristics of impedance matching. Generally the VSWR must lie in the range of 1 and 2 for a suitable impedance matching. Thus the planned aerial has the VSWR of 1.24 , which might be beneath 2 at $25 \mathrm{GHz}$.

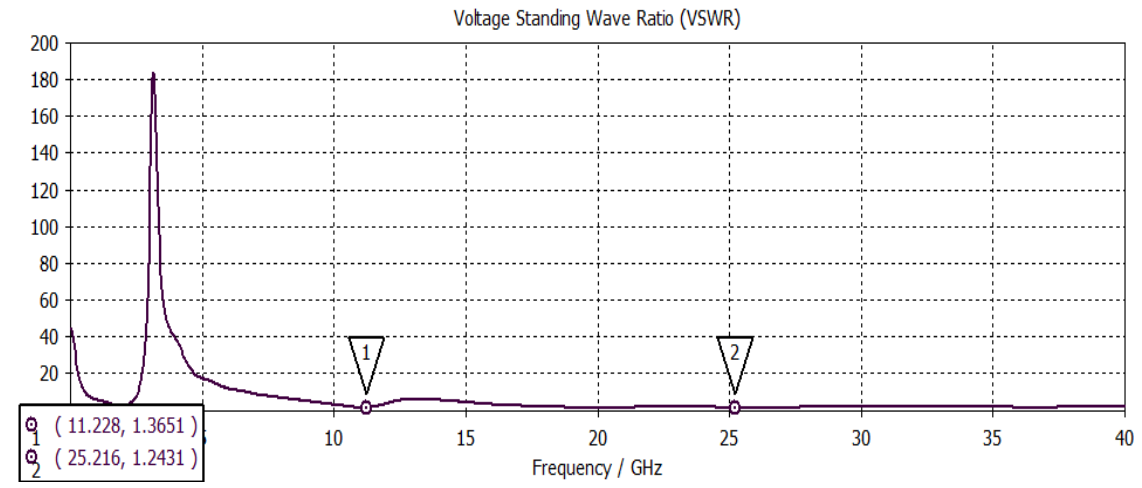

Figure 5: VSWR for Single FR 4 Substrate. 


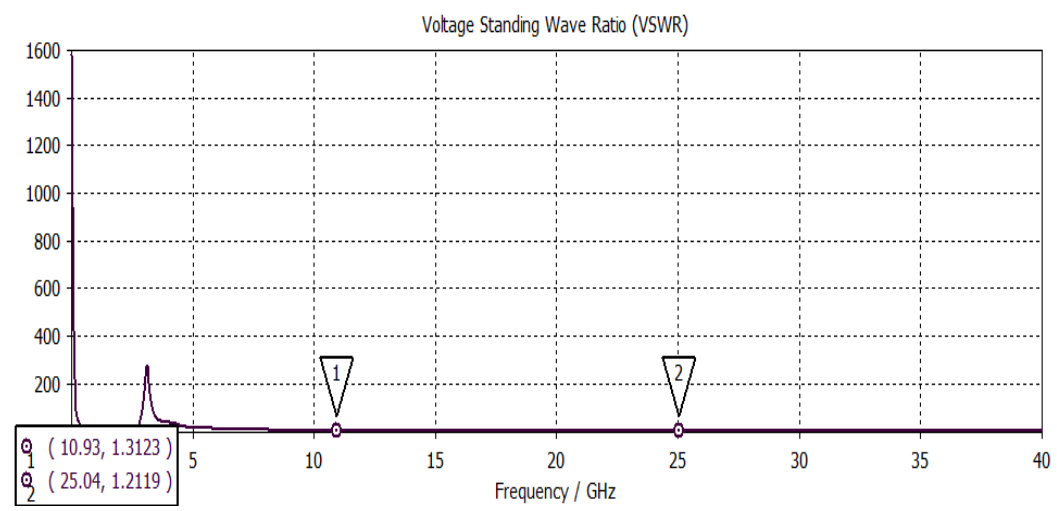

Figure 6: VSWR for Dual FR-4 Substrate.

\section{Radiation Pattern (Directivity)}

Antennas do not radiate the energy uniformly in all the directions in practice. The energy representation may be the graphical notation of energy distribution of 3-D mode and it is calculated in far field region. The power of radiation is calculated in relevance to the field strength in reference to a specific level (Main Beam). The directivity of the planned aerial is $6.53 \mathrm{dBi}$ for the frequency $25 \mathrm{GHz}$ which is revealed in the figure 7 . Figure 8 illustrates the directivity of the planned aerial with dual substrate which has the directivity of $5.82 \mathrm{dBi}$ at $25 \mathrm{GHz}$.

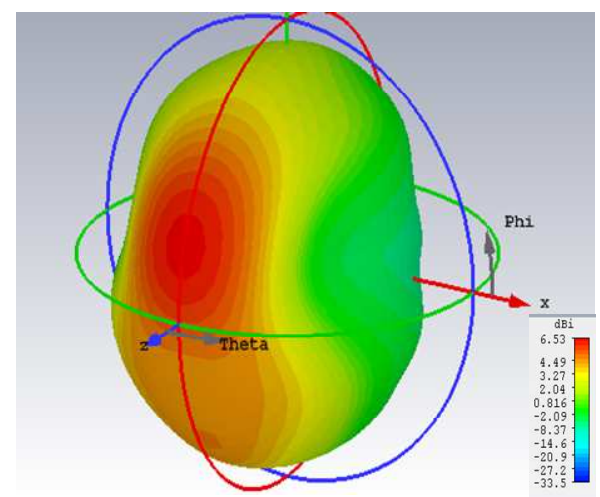

Figure 7: Directivity of Planned Aerial with Single FR-4 Substrate.

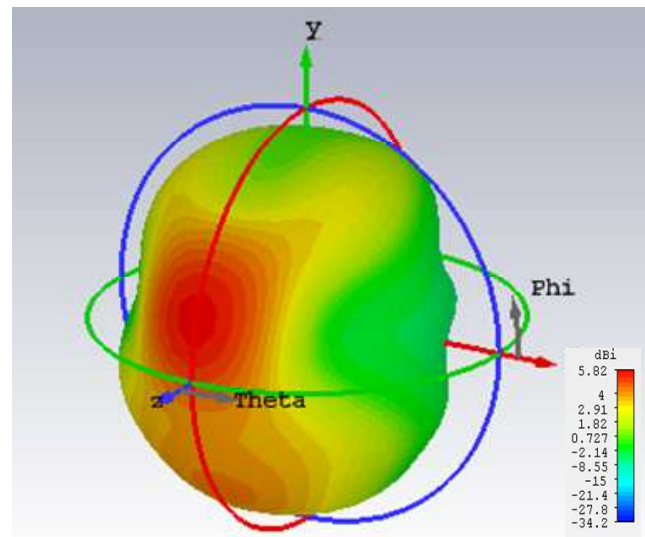

Figure 8: Directivity of Planned Aerial with Dual FR-4 Substrate. 


\section{Radiation Pattern (Gain)}

Gain depicts the quantity of power to be sent out in the path of max out emission towards with an isotropic source. The gain for the planned aerial at $25 \mathrm{GHz}$ is $4.51 \mathrm{~dB}$ which is revealed in figure 11. For the planned aerial of dual FR-4 the gain is $3.78 \mathrm{~dB}$ which is revealed in figure 12 .

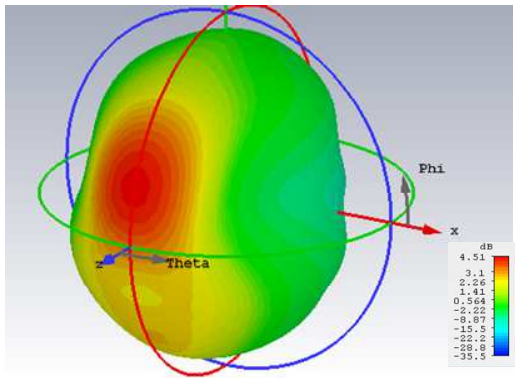

Figure 11: Gain of Single FR4 Substrate.

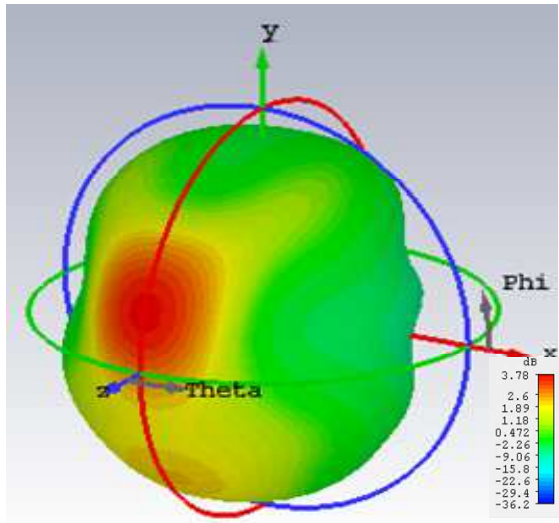

Figure 12: Gain of Dual FR-4 Substrate.

\section{CONCLUSIONS}

The square patch antenna for the single and dual FR 4 substrate is designed and simulated and its parameters like Return Loss, VSWR, Directivity and Gain simulated results are revealed above. The return loss is $-24.0 \mathrm{~dB}$ for the planned aerial of dual substrate FR-4. VSWR together with the designed antenna is beneath 2. Directivity and Gain for dual FR 4 is 5.82 $\mathrm{dBi}$ and $3.78 \mathrm{~dB}$ at $25 \mathrm{GHz}$. Thus the feigned outcomes of the planned aerial find use in Ka band applications.

\section{REFERENCES}

1. J.-W. Kim, T.-H. Jung, H.-K. Ryu, J.-M. Woo, C.-S. Eun, and D.-K. Lee, "Compact multiband microstrip antenna using inverted-L- and T-shaped parasitic elements," IEEE Antennas and Wireless Propagation Letters, Vol. 12, pp. 1299-1302, 2013.

2. C.-L. Mak, H. Wong, and K.-M. Luk, "High-gain and wide-band single-layer patch antenna for wireless communications," IEEE Transactions on Vehicular Technology, Vol. 54, No. 1, pp. 33-40, 2005.

3. Nishiyama, E., Aikawa, M., and Egashira, S., "Stacked microstrip antenna for wideband and high gain," IEE Proc.Microwave Antennas Propagation, 151, pp. 143-148, 2004. 
4. Sievenpiper, D., Zhang, L., Jimenez Broas, R.F., Alexopoulos, N.G., and Yablonovitch, E., "High impedance electromagnetic surfaces with a forbidden frequency band," IEEE Trans. Microwave Theory Techn., Vol. 47, pp. 2059-2074, 1999.

5. Xi Chen, Long Li, Chang Hong Liang, Zi Jian Su, and Cheng Zhu, "Dual-Band High Impedance Surface With MushroomType Cells Loaded by Symmetric Meandered Slots, ” IEEE Trans. Antennas Propag., Vol. 60, pp. 4670-4687, 2012.

6. Xi Chen, Long Li, Chang Hong Liang, Zi Jian Su, and Cheng Zhu, "Dual-Band High Impedance Surface With MushroomType Cells Loaded by Symmetric Meandered Slots,” IEEE Trans. Antennas Propag., Vol. 60, pp. 4670-4687, 2012.

7. D. M. Pozar, Microwave Engineering, John Wiley \& Sons, New York, NY, USA, 4th edition, 2012.

8. Oh, S.S., and Shafai, L., "Artificial magnetic conductor using split ring resonators and its applications to antennas," Microwave Opt. Technol. Lett., Vol. 48, pp. 329-334, 2006.

9. Amit Kumar Gupta, R.K. Prasad, Dr. D.K. Srivastava "Design And Development Of Dual E- Shaped Microstrip Patch Antenna For Bandwidth And Gain Enhancement” IJECET ISSN 0976 - 6464(Print) ISSN 0976 -6472(Online) Volume 3, Issue 3, October-December (2012), Pp. 34-42.

10. Balanis, C.A., “Antenna Theory: Analysis and Design,” (John Wiley \& Sons INC., 3rd edn., 2005).

11. Neeraj Rao and Dinesh Kumar V. "Gain and Bandwidth Enhancement of a Microstrip Antenna Using Partial Substrate Removal in Multiple-layer Dielectric Substrate" Progress in Electromagnetic Research Symposium Proceedings, Suzhou, China, Sept. 12-16, 2011 Page no-1285.

12. Pampa Debnath, Sohini Pal, Amrita Maity, Riya Bhattacharyya, Krishna Mahato "Design and Enhancement of Gain \& Bandwidth of Rectangular Patch Antenna Using Shifted Semi-Circular Slot Technique” International Journal of Advanced Research in Computer and Communication Engineering Vol. 3, Issue 4, April 2014.

13. Manas Ranjan Jena, B.B. Mangaraj and Debasis Mishra "Bandwidth and Gain Enhancement of Multiband Fractal Antenna Based on the Sierpinski Carpet Geometry” ICTACT Journal on Communication Technology, March 2013, Volume: 04, Issue: 01.

14. Anwer Sabah Mekki, Mohd Nizar Hamidon, Alyani Ismail, and Adam R. H. Alhawari "Gain Enhancement of a Micro strip Patch Antenna Using a Reflecting Layer" Hindawi Publishing Corporation. International Journal of Antennas and Propagation, Received 20 December 2014; Revised 5 March 2015; Accepted 5 March 2015.

15. Mst. Nargis Aktar, Muhammad Shahin Uddin, Md. Ruhul Amin, and Md. Mortuza Ali "Enhanced Gain and Bandwidth of Patch Antenna Using EBG Substrates" International Journal Of Wireless \& Mobile Networks (IJWMN) Vol. 3, No. 1, February 2011.

16. H. Okabe and K. Takei, "Tunable antenna system for $1.9 \mathrm{GHz}$ PCS handsets," IEEE Antennas Propag. Int. Symp., Vol. 1, pp. 166- 169, 2001.

17. K. Chung, Y. Nam, T. Yun and J. Choi, "Reconfigurable microstrip patch antenna with switchable polarization," ETRI Journal, Vol. 28, No. 3, 2006.

18. P. Muthili, P. Cherian, S. Mridula and D. Paul, "Design of a compact multi-band microstrip antenna," 2009 Annual India Conf., pp. 1-4, 2009.

19. H.-C. Ryu, H.-R. ahn, S.-H. Lee and W. S. Park, "Triple-stacked microstrip patch antenna for multiband system," Elect. Lett., vol. 38, no. 24, pp. 1496-1497, 2002.

20. D. Peroulis, K. Sarabandi and L. B. P. Katehi, “Design of reconfigurable slot antennas," IEEE Trans. Antennas Propag., vol. 53, no. 7, pp. 645-654, 2005. 
21. Likitha, P., and M. Surendra Kumar. "Design and Analysis of Square Patch Antenna and Its Arrays at 5 GHZ." International Journal of Electronics and Communication Engineering (IJECE) 6.1 (2017): 17-26.

22. Varaprasad, S. Phani, and R. Prasad Rao. "Design and Analysis of a Multi Layer Substrate Single Patch Microstrip Patch Antenna for Enhancing the Beam Width with Control on Directivity." IASET: International Journal of Electronics and Communication Engineering (IJECE) 6.1 (2017):47-52

23. Sharma, Sushant, and Gurpreet Kumar. "A dual Wideband Stair Shape Microstrip Patch Antenna for $C$ \& $X$ Band." International Journal of Electronics and Communication Engineering (IJECE) 5.4 (2016): 1-8.

24. Agrawal, Akash, Narendra Kumar Garg, and Rahul Sharma. "Accretion in Parameters of Rectangular Microstrip Patch Antenna with Metamaterial." IMPACT: International Journal of Research in Engineering \& Technology (IMPACT: IJRET) 2.10 (2014): $39-46$

25. Barik, Biswa Ranjan, and A. Kalirasu. "Performance Indicators of Rectangular Microstrip Patch Antenna." International Journal of Mechanical and Production Engineering Research and Development (IJMPERD) 9.3 (2019): 1515-1526

26. Barik, Biswa Ranjan, and A. Kalirasu. "Designing of Trapezium Cut Shape Microstrip Antenna in X Band." International Journal of Electrical and Electronics Engineering Research (IJEEER) Special Issue (2016): 145-152 

